\title{
High Throughput Light Absorber Discovery, Part 2: Establishing Structure-Band Gap Energy Relationships
}

\author{
Santosh K. Suram, ${ }^{\dagger}$ Paul F. Newhouse, ${ }^{\dagger}$ Lan Zhou, ${ }^{\dagger}$ Douglas G. Van Campen, $^{\dagger}$ Apurva Mehta, ${ }^{\ddagger}$
} and John M. Gregoire*, ${ }^{\dagger}$

$\dagger$ Joint Center for Artificial Photosynthesis, California Institute of Technology, Pasadena California 91125, United States

${ }^{\ddagger}$ Stanford Linear Accelerator Laboratory, Stanford University, Menlo Park, California 94025, United States

\section{Supporting Information}

ABSTRACT: Combinatorial materials science strategies have accelerated materials development in a variety of fields, and we extend these strategies to enable structure-property mapping for light absorber materials, particularly in high order composition spaces. High throughput optical spectroscopy and synchrotron X-ray diffraction are combined to identify the optical properties of $\mathrm{Bi}-\mathrm{V}-\mathrm{Fe}$ oxides, leading to the identification of $\mathrm{Bi}_{4} \mathrm{~V}_{1.5} \mathrm{Fe}_{0.5} \mathrm{O}_{10.5}$ as a light absorber with direct band gap near $2.7 \mathrm{eV}$. The strategic combination of experimental and data analysis techniques includes automated Tauc analysis to estimate band gap energies from the high throughput spectroscopy data, providing an automated platform for identifying new optical materials.

KEYWORDS: high-throughput screening, combinatorial science, band gap, UV-vis spectroscopy, optical spectroscopy, solar fuels

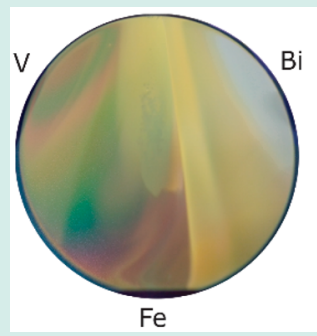

\section{INTRODUCTION}

Mapping of structure-property relationships enables accelerated discovery of functional materials, particularly when the target material must meet well-defined criteria. ${ }^{1}$ For light absorbers, a band gap energy in the visible to near-ultraviolet range is important for enabling efficient utilization of the solar spectrum, and the lack of sufficient metal oxides with a desirable band gap has motivated the application of several materials discovery strategies. ${ }^{2}$ High-throughput (HiTp) materials theory and materials informatics efforts have made tremendous progress in advancing the understanding of structure-property relationships for a variety of applications. ${ }^{1,3}$ In addition to these efforts, rapid mapping of structure and property using experimental data is essential to establish robust structure-property relationships that inherently incorporate the effects of synthesis and processing parameters. ${ }^{1,4}$ HiTp combinatorial synthesis methods enable access to relatively unexplored higher-order (more than two elements or compositional degrees of freedom) composition spaces that are difficult to treat using computational methods due to the vast set of possible crystallographic configurations. ${ }^{5}$ To establish composition-structure-property relationships, HiTp synthesis methods must be paired with robust structural and property characterization tools, and in the present work, we describe strategic combinations of HiTp optical spectroscopy and X-ray diffraction (XRD) experiments to identify crystal structureband gap relationships for discovery of solar absorber materials. While the term "structure" has a variety of meanings in

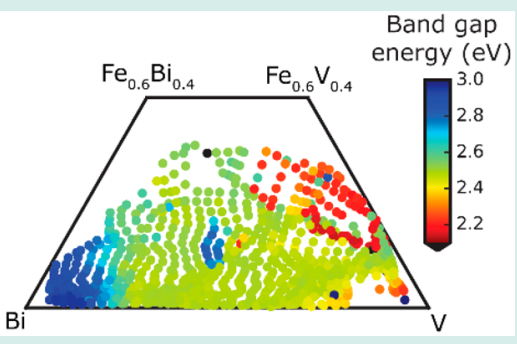

chemistry and materials science, it denotes the crystal structure of a solid state material in the present work.

HiTp discovery of optical materials enables important advancements in applications such as phosphors, photovoltaics, smart windows, and solar photochemistry. For solar energy applications, mapping optical properties across composition libraries has been successfully employed for the discovery and understanding of transparent conductive oxides ${ }^{6}$ and light absorbers. ${ }^{2 c}$ These combinatorial experiments can be tailored to study detailed features such as the optical effects of semiconductor doping ${ }^{7}$ and can also characterize component and device-level optical properties of photovoltaic cells. ${ }^{8}$ For the purposes of discovering solar light absorbers, the band gap energy is the most critical parameter, and for emerging technologies such as solar fuel generation, light absorber discovery is paramount to technology development. ${ }^{2 a, 9} \mathrm{We}$ have recently demonstrated a HiTp instrument capable of measuring transmittance and reflectance spectra at a throughput better than 1 sample per second, ${ }^{10}$ and in the present work, we use a similar HiTp instrument that acquires spectra in a diffuse reflectance geometry. In part 1 of this twopart series, we demonstrate an automated Tauc analysis algorithm that extracts the band gap energy from experimental Tauc patterns using constrained piecewise linear fitting. In this

Received: April 9, 2016

Revised: September 8, 2016

Published: September 23, 2016 
second part, we apply this algorithm to HiTp optical spectroscopy data on composition libraries.

In computational theory ${ }^{2 \mathrm{~d}, \mathrm{e}}$ and materials informatics approaches $^{11}$ to the discovery and understanding of optical materials, optical properties are typically related to a crystal structure with an associated composition. Likewise, experimental characterization of crystal structure is critical to understanding optical materials, and XRD is a ubiquitous technique for structural characterization. Several synchrotron experiments have been recently developed and optimized for specific library formats and types of XRD measurements, ${ }^{12}$ including our recent XRD experiment designed for thin film libraries. ${ }^{13}$ By solving the phase behavior of a composition library using HiTp XRD, comparison with optical characterization provides direct mapping of structure-property relationships. $^{14}$

Since the initial demonstration of water splitting with single crystal $\mathrm{TiO}_{2}$ (band gap approximately $3.0 \mathrm{eV}$ ), ${ }^{15}$ a primary materials challenge has been the discovery of metal oxides with lower band gap energy. While the optimal band gap energy depends on device configuration and is below $2 \mathrm{eV}$ for many tandem light absorber architectures, ${ }^{16}$ the identification of new light absorbers in the visible to ultraviolet range is a bottleneck in the development of photoanodes that meet a broader range of material requirements including photoelectrochemical stability and catalytic activity for the oxygen evolution reaction. In this context, we demonstrate the application of a foundational platform combining combinatorial thin film synthesis, HiTp XRD, and HiTp UV-vis measurements coupled with automated Tauc analysis for rapid identification of composition-structure-optical property relationships. While these relationships may differ from those of bulk materials due to thin-film effects such as strain and grain size, we note that solar energy technologies typically employ thinfilm light absorbers, and to promote accelerated translation from materials discovery to device implementation, ${ }^{5 a}$ it is important to perform material discovery experiments using a pertinent materials format and scalable, reproducible ${ }^{17}$ synthesis technique.

In the present work, we demonstrate the materials discovery platform with a cosputtered $(\mathrm{Bi}-\mathrm{V}-\mathrm{Fe}) \mathrm{O}_{x}$ continuouscomposition-spread thin film by performing UV-vis measurements on 1521 composition samples and solving the phase behavior using XRD spectra measured on 177 composition samples. The $(\mathrm{Bi}-\mathrm{V}-\mathrm{Fe}) \mathrm{O}_{x}$ system is of particular interest for solar fuels applications given the propensity of $\mathrm{BiVO}_{4}$ and $\mathrm{Fe}_{2} \mathrm{O}_{3}$ in the solar fuels literature. ${ }^{2 \mathrm{a}, 18}$ We extract structureband gap energy relationships for five oxide phases in the $(\mathrm{Bi}-$ $\mathrm{V}-\mathrm{Fe}) \mathrm{O}_{x}$ composition space, identifying $\mathrm{Bi}_{4} \mathrm{~V}_{1.5} \mathrm{Fe}_{0.5} \mathrm{O}_{10.5}$ as a promising solar fuels photoanode with a direct band gap near $2.7 \mathrm{eV}$.

\section{EXPERIMENTAL AND DATA ANALYSIS}

Synthesis. The continuous composition spread of $\mathrm{Bi}, \mathrm{V}$, and $\mathrm{Fe}$ was synthesized by magnetron cosputtering in the presence of $\mathrm{Ar}$ as carrier gas from elemental sources arranged symmetrically with respect to the $100 \mathrm{~mm} \mathrm{Si} / \mathrm{SiO}_{2}$ substrate. The spatial variation in deposition rate from each source resulted in a continuous thin film with composition gradient on the order of 1 atom $\% \mathrm{~mm}^{-1}$. The relative deposition rates were chosen with the aim to obtain a composition of $\mathrm{Bi}_{40} \mathrm{Fe}_{5} \mathrm{~V}_{55}$ at the substrate center. The variation in the deposition rates among different sources resulted in thickness variation across the library within a factor of 2 of the center thickness of 200 $\mathrm{nm}$. The as-deposited metal composition library was calcined in air at $773 \mathrm{~K}$ for $8 \mathrm{~h}$, producing the metal oxide $(\mathrm{Bi}-\mathrm{V}-\mathrm{Fe}) \mathrm{O}_{x}$ library.

Composition and Structure Measurements and Analysis. For the $(\mathrm{Bi}-\mathrm{V}-\mathrm{Fe}) \mathrm{O}_{x}$ library, composition and structural measurements were acquired using a custom HiTp Xray fluorescence (XRF) and $\mathrm{XRD}$ setup incorporated into the bending-magnet beamline 1-5 of the Stanford Synchrotron Radiation Light source (SSRL) at SLAC National Accelerator Laboratory. A detailed description of the experiment is provided by Gregoire et al. ${ }^{13}$ Briefly, using a monochromated $13.5 \mathrm{keV}$ source in reflection scattering geometry with $1 \mathrm{~mm}^{2}$ footprint on the sample, XRD and XRF data were acquired simultaneously using a Princeton Quad-RO 4320 and a Si drift detector coupled to an XIA digital signal processor, respectively. Measurements were taken on a square grid with $6 \mathrm{~mm}$ pitch and within a radius of $44 \mathrm{~mm}$ of the $100 \mathrm{~mm}$ diameter library. Diffraction images were transformed into reciprocal space using calibration parameters derived from a $\mathrm{LaB}_{6}$ standard and integrated down to powder patterns (intensity versus $Q$ ) using WxDiff software. ${ }^{19}$ Background subtraction of the integrated XRD pattern was performed with a custom algorithm that models the background using cubic splines.

Single channel analyzers (SCAs) were used to record the $\mathrm{Bi}$ $\mathrm{M}, \mathrm{V} \mathrm{K}$, and Fe K XRF intensities for each sample. A singlepoint calibration of the relative sensitivity factors of the SCA measurements was obtained using a separate composition measurement at substrate center, which was performed with an Oxford Instruments X-Max $80 \mathrm{~mm}^{2}$ energy dispersive X-ray spectroscopy (EDS; Oxford Instrument, Concord, MA) detector on an FEI Nova NanoSEM 450 (FEI, Hillsboro, $\mathrm{OR}, 15 \mathrm{keV}$ electron beam). The absolute composition uncertainty for this EDS measurement is 10 atom \%, and the XRF-determined relative compositions, which enable composition-property maps, have better than 1 atom \% sensitivity. The accurate determination of sample compositions is supported by the excellent agreement between the stoichiometry of each of the three high-purity phases and the composition of the sample at which the highest purity is observed.

Constructing a phase map from the set of 177 XRD patterns was performed using a semiautomated approach. While supervised and unsupervised learning algorithms are being actively developed to enable automated phase mapping on combinatorial materials libraries, ${ }^{20}$ we observed that the phase behavior was readily understood via manual inspection of the present data set, and we identified the presence of five phases by examining XRD data using the UDiscoverIt software package. ${ }^{21}$ The crystal structures of these phases were identified by matching the XRD patterns of representative compositions with database patterns from the International Center for Diffraction Data (ICDD) using DIFFRAC.SUITE EVA software. By inspecting the ICDD patterns of these phases, we established a representative Bragg peak for each phase that was unique and distinguishing among the set of five phases. By definition of a $Q$-range in which only the representative peak exhibited finite scattering intensity, the peak intensity was calculated by performing a local integration of each XRD pattern, which was then scaled by the ICDD database value of the relative scattering intensity of the peak. This calculation produced the relative intensity of the five phases for each of the 
a)

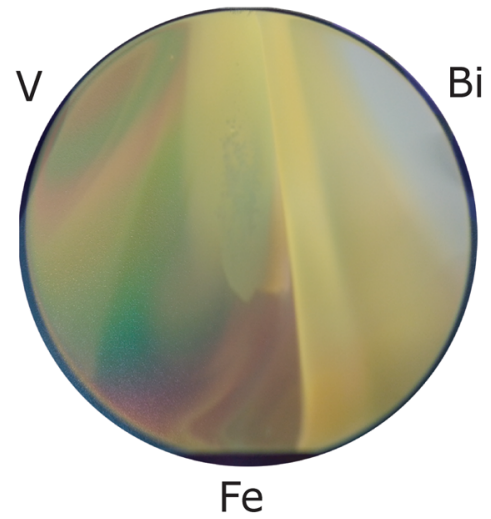

$$
\frac{\mathrm{Bi}_{8} \mathrm{~V}_{2} \mathrm{O}_{17}}{00-044-0171}
$$

$$
\begin{gathered}
\mathrm{Bi}_{4} \mathrm{~V}_{1.5} \mathrm{Fe}_{0.5} \mathrm{O}_{10.5} \\
01-087-1539
\end{gathered}
$$

\begin{tabular}{|c||c|c|c|}
$\mathrm{BiVO}_{4}$ & $\mathrm{FeVO}_{4}$ & $\mathrm{~V}_{2} \mathrm{O}_{5}$ \\
$01-074-4894$ & $00-038-1372$ & $01-089-06$
\end{tabular}

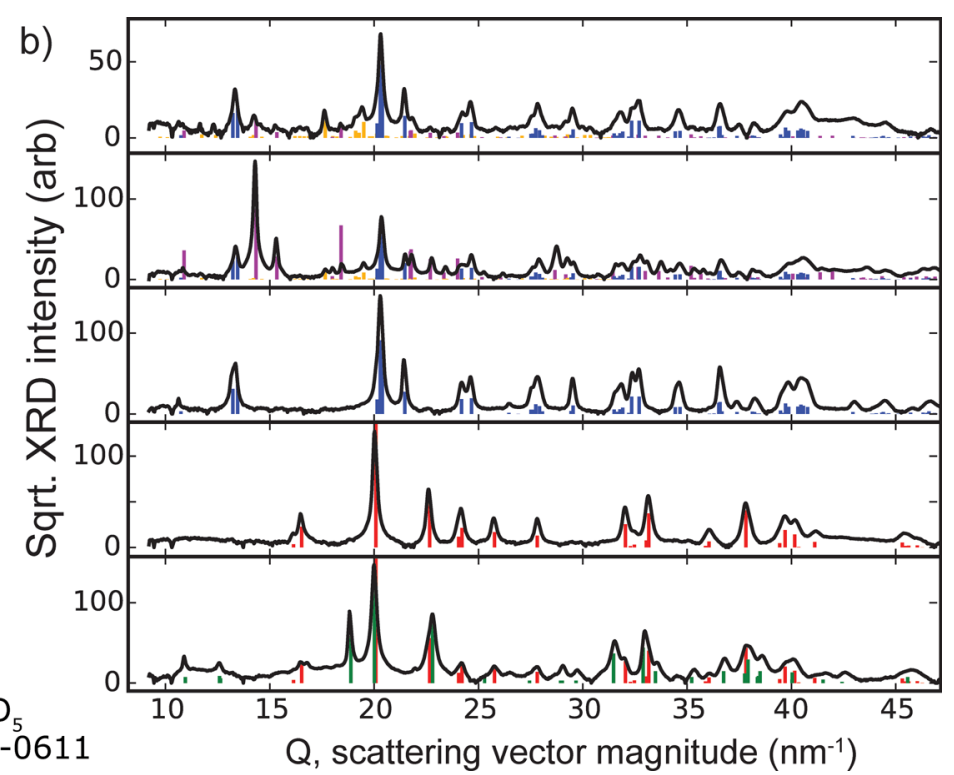

Figure 1. (a) White-light illuminated image of the sputter-deposited ( $\mathrm{Bi}-\mathrm{V}-\mathrm{Fe}) \mathrm{O}_{x}$ composition library. (b) Representative XRD patterns showing the presence of $\mathrm{Bi}_{8} \mathrm{~V}_{2} \mathrm{O}_{17}$ (orthorhombic), $\mathrm{Bi}_{4} \mathrm{~V}_{1.5} \mathrm{Fe}_{0.5} \mathrm{O}_{10.5}$ (tetragonal), $\mathrm{BiVO}_{4}$ (monoclinic), $\mathrm{FeVO}_{4}$ (anorthic), and $\mathrm{V}_{2} \mathrm{O}_{5}$ (orthorhombic) phases. The ICDD entry of each phase is provided in the legend.

177 composition samples, and subsequent normalization within each composition sample yielded the phase fractions.

Optical Characterization. Optical characterization of the $(\mathrm{Bi}-\mathrm{V}-\mathrm{Fe}) \mathrm{O}_{x}$ library was performed on a custom HiTp diffuse reflectance (DR) instrument built to analyze light absorbers on opaque substrates. The computer-automated experiment proceeded by translating the composition library below a spectrometer consisting of a $200 \mathrm{~W} \mathrm{Hg}(\mathrm{Xe})$ lamp (Newport/ Oriel Apex) and an integrating sphere (Ocean Optics ISP-50-8R-GT) that was fiber-coupled to a spectrometer (Spectral Products, Inc. SM303). ${ }^{10}$ An absorbing plug was incorporated into the integrating sphere to exclude the specular reflection of the illumination that impinged the samples at $8^{\circ}$, and as a result the DR signal was comprised of light scattered beyond approximately $6.5^{\circ}$ of the specular reflection and less than $44^{\circ}$ from substrate normal. DR spectra were acquired on a square grid of 1521 positions in the $(\mathrm{Bi}-\mathrm{V}-\mathrm{Fe}) \mathrm{O}_{x}$ library with an integration time of $0.01 \mathrm{~s}$ per spectrum, and typically three spectra were averaged to produce the DR spectrum for each sample.

The optical spectra were converted into a property $\beta$ that is proportional to absorption coefficient $(\alpha)$ using the KubelkaMunk radiative transfer model, ${ }^{22}$ as detailed in part 1 of this series. The normalized Tauc property was calculated as TP = $(\beta h \mathrm{v})^{1 / n} / \max \left((\beta h \mathrm{v})^{1 / n}\right)$, where $n$ is the Tauc exponent whose value is $1 / 2$ for analysis of direct-allowed (DA) electronic transitions. The plots of DA Tauc property $\left(T P^{\mathrm{DA}}\right)$ vs photon energy $(h \nu)$ were analyzed to estimate band gap using the Tauc analysis encoded into a constrained piecewise linear fitting algorithm, as described in part 1 of this series. We note that for discovery of photoabsorbers, IA transitions are of primary interest when the direct band gap is at substantially higher energy, in which case the significantly lower IA band gap can provide insight into composition-dependent phenomena such as band gap tuning. For the $(\mathrm{Bi}-\mathrm{V}-\mathrm{Fe}) \mathrm{O}_{x}$ library investigated in this work, we performed Tauc analysis of indirect-allowed (IA) transitions and did not observe an IA band gap more than
$0.3 \mathrm{eV}$ below the respective DA band gap, prompting our focus on DA band gaps in the present work.

\section{RESULTS AND DISCUSSION}

Figure 1a shows a white-light illuminated image of the (Bi-V$\mathrm{Fe}) \mathrm{O}_{x}$ library in which several regions with distinct colors are observed. The region closest to the $\mathrm{V}$ source and extending toward the $\mathrm{Fe}$ source appears to alternate in color between green and red, a classic indication of thin film interference fringes. The region closest to the Bi source appears gray and colorless, and the most pronounced optical feature in the image is a bright yellow-colored region that vertically spans the center of the wafer, which has neighboring dull-yellow regions on either side.

The synchrotron XRD characterization of the $(\mathrm{Bi}-\mathrm{V}-\mathrm{Fe}) \mathrm{O}_{x}$ library yielded XRD patterns with excellent signal-to-noise, particularly due to the design of a scattering geometry that mitigated background signal from the $\mathrm{Si} / \mathrm{SiO}_{2}$ substrate. Figure $1 \mathrm{~b}$ contains representative XRD patterns from the $177 \mathrm{HiTp}$ XRD measurements along with ICDD patterns of the five identified phases (orthorhombic $\mathrm{Bi}_{8} \mathrm{~V}_{2} \mathrm{O}_{17}$, tetragonal $\mathrm{Bi}_{4} \mathrm{~V}_{1.5} \mathrm{Fe}_{0.5} \mathrm{O}_{10.5}$, monoclinic $\mathrm{BiVO}_{4}$, anorthic $\mathrm{FeVO}_{4}$, and orthorhombic $\mathrm{V}_{2} \mathrm{O}_{5}$ ).

Figure 2 shows the estimated phase fraction of each phase as a function of cation composition. $\mathrm{BiVO}_{4}, \mathrm{Bi}_{4} \mathrm{~V}_{1.5} \mathrm{Fe}_{0.5} \mathrm{O}_{10.5}$, and $\mathrm{V}_{2} \mathrm{O}_{5}$ are observed with high phase purity at select composition samples within the library. The maximum observed phase fractions of $\mathrm{Bi}_{8} \mathrm{~V}_{2} \mathrm{O}_{17}$ and $\mathrm{FeVO}_{4}$ are 0.73 and 0.44, respectively, and the lack of phase purity of these phases is expected since the composition library did not include the corresponding cation stoichiometries. For single-phase composition samples, the measured band gap energy can be directly associated with a phase. In multiphase regions of the composition library, structure-band gap relationships require more detailed interpretation, for which a dense sampling of optical measurements is beneficial.

Automated Tauc analysis of the $1521 \mathrm{TP} \mathrm{DA}^{\mathrm{DA}}$ spectra yielded a direct band gap estimation for 1069 samples, and for 179 of 

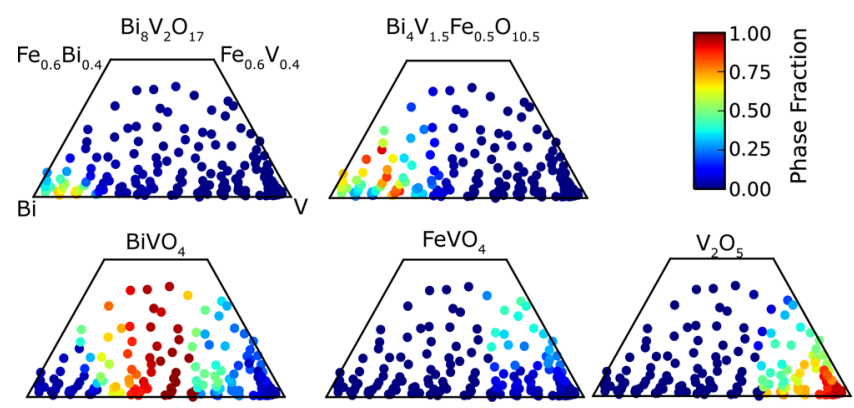

Figure 2. False color representation of phase fractions of $\mathrm{Bi}_{8} \mathrm{~V}_{2} \mathrm{O}_{17}$, $\mathrm{Bi}_{4} \mathrm{~V}_{1.5} \mathrm{Fe}_{0.5} \mathrm{O}_{10.5}, \mathrm{BiVO}_{4}, \mathrm{FeVO}_{4}$, and $\mathrm{V}_{2} \mathrm{O}_{5}$ as a function of cation composition.

these $T P^{\mathrm{DA}}$ spectra, a second direct band gap was also identified. We note that the identification of a DA band gap in these materials does not guarantee that they are direct-gap semiconductors, since a lower-energy, weakly absorbing indirect or forbidden transition may exist. As noted above, no indirect-allowed band gaps with energy in excess of $0.3 \mathrm{eV}$ below $E_{\mathrm{g}}^{\mathrm{DA}}$ were identified in the automated Tauc analysis. In Figure 3 , the compositions with a single band gap $\left(E_{\mathrm{g}}^{\mathrm{DA}}\right)$ are

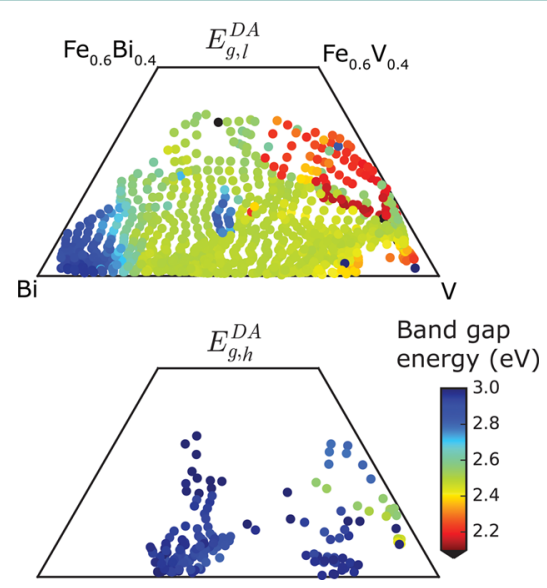

Figure 3. (top) The composition map of the direct-allowed band gap energy is shown for the $(\mathrm{Bi}-\mathrm{V}-\mathrm{Fe}) \mathrm{O}_{x}$ library. The samples in which a single band gap was identified are shown along with the lower-energy $\left(E_{\mathrm{g}, 1}^{\mathrm{DA}}\right)$ gap for the dual-band gap samples. (bottom) The higher-energy $\left(E_{g, h}^{\mathrm{DA}}\right)$ direct allowed band gap of the dual-band gap samples is shown.

plotted along with the lower-energy band gap $\left(E_{\mathrm{g}, 1}^{\mathrm{DA}}\right)$ of the dual-band gap samples, and the compositions with a second, higher band gap energy $\left(E_{\mathrm{g}, \mathrm{h}}^{\mathrm{DA}}\right)$ are plotted separately. Comparison of Figures 2 and 3 reveals that a single band gap is identified in the composition regions with a high phase fraction of $\mathrm{BiVO}_{4}$ or $\mathrm{Bi}_{4}\left(\mathrm{~V}_{1.5} \mathrm{Fe}_{0.5} \mathrm{O}_{10.5}\right)$, and no band gap is reported in the $\mathrm{V}_{2} \mathrm{O}_{5}$-rich region. In the multiphase regions, the composition-structure-band gap trends can be summarized as follows: the band gap energy smoothly varies with composition in the $\mathrm{Bi}_{4} \mathrm{~V}_{1.5} \mathrm{Fe}_{0.5} \mathrm{O}_{10.5}$ and $\mathrm{Bi}_{8} \mathrm{~V}_{2} \mathrm{O}_{17}$ multiphase region; the band gap energy rapidly decreases by $0.2-0.3 \mathrm{eV}$ when the phase fraction of $\mathrm{FeVO}_{4}$ exceeds approximately $30 \%$; two band gaps are identified for some of the samples with both $\mathrm{FeVO}_{4}$ and $\mathrm{BiVO}_{4}$; two band gaps are identified in many compositions containing both $\mathrm{BiVO}_{4}$ and $\mathrm{Bi}_{4} \mathrm{~V}_{1.5} \mathrm{Fe}_{0.5} \mathrm{O}_{10.5}$; and two band gaps are identified in some samples containing both $\mathrm{BiVO}_{4}$ and $\mathrm{V}_{2} \mathrm{O}_{5}$.
To illustrate the band gap estimation and provide quantitative estimation of the band gap energy of each phase, several representative $T P^{\mathrm{DA}}$ plots are shown in Figure 4. Figure 4a demonstrates the band gap estimation for $\mathrm{BiVO}_{4}$, the most widely studied ternary oxide phase in this composition library. The band gap energy $\left(E_{\mathrm{g}}^{\mathrm{DA}}=2.5 \mathrm{eV}\right)$ is in excellent agreement with the literature value, as is the identification of a slightly smaller IA band gap (see Figure $\mathrm{S} 1, E_{\mathrm{g}}^{\mathrm{IA}}=2.44 \mathrm{eV}$ ), ${ }^{18,23}$ demonstrating the fidelity of our techniques.

Figure $4 \mathrm{~b}$ shows analogous analysis of $\mathrm{Bi}_{4} \mathrm{~V}_{1.5} \mathrm{Fe}_{0.5} \mathrm{O}_{10.5}$, for which a literature band gap energy could not be identified. Since the samples of Figure $4 \mathrm{~b}$ correspond to a high phase purity of $\mathrm{Bi}_{4} \mathrm{~V}_{1.5} \mathrm{Fe}_{0.5} \mathrm{O}_{10.5}$ with thin film compositions that closely match the stoichiometry of the phase, we report the direct band gap of this quaternary oxide to be $E_{\mathrm{g}}^{\mathrm{DA}}=2.7 \pm 0.1$ $\mathrm{eV}$ (uncertainty is reported based on the range of band gap values resulting from the Tauc analysis of the five samples with highest phase purity). Figure $4 \mathrm{c}$ shows $T P^{\mathrm{DA}}$ spectra for several compositions with lower $\mathrm{Fe}$ and higher $\mathrm{Bi}$ concentration than the phase-pure $\mathrm{Bi}_{4} \mathrm{~V}_{1.5} \mathrm{Fe}_{0.5} \mathrm{O}_{10.5}$ samples of Figure $4 \mathrm{~b}$. The band gap shifts gradually from the $2.7 \mathrm{eV}$ value of $\mathrm{Bi}_{4} \mathrm{~V}_{1.5} \mathrm{Fe}_{0.5} \mathrm{O}_{10.5}$ as a function of composition, which can be indicative of band gap variation with alloy composition (band gap tuning), and indeed alloying of the form $\mathrm{BiV}_{2-x} \mathrm{Fe}_{x} \mathrm{O}_{11-x}$ has been observed in this system. ${ }^{24}$ These samples contain not only $\mathrm{Bi}_{4} \mathrm{~V}_{1.5} \mathrm{Fe}_{0.5} \mathrm{O}_{10.5}$ but also $\mathrm{Bi}_{8} \mathrm{~V}_{2} \mathrm{O}_{17}$, and the blue-shifting of the band gap from the $\mathrm{Bi}_{4} \mathrm{~V}_{1.5} \mathrm{Fe}_{0.5} \mathrm{O}_{10.5}$ value could be due to optical absorption effects from the increasing phase fraction of $\mathrm{Bi}_{8} \mathrm{~V}_{2} \mathrm{O}_{17}$. Deconvolving these signals is particularly difficult since $\mathrm{Bi}_{8} \mathrm{~V}_{2} \mathrm{O}_{17}$ was not synthesized in high purity in this library, but we did not further pursue this band gap shift into the ultraviolet range, which is a departure from the primary range of interest for solar absorber applications. While the $\mathrm{Bi}_{4} \mathrm{~V}_{1.5} \mathrm{Fe}_{0.5} \mathrm{O}_{10.5}$ phase has been studied for ionic conduction ${ }^{24}$ and ferroelectric functionalities, ${ }^{25}$ optical characterization has been lacking in the literature, and the direct band gap is near that of the well-studied $\mathrm{BiVO}_{4}$ phase. ${ }^{18}$

Figure $4 \mathrm{~d}$ shows estimation of two band-gaps, $E_{\mathrm{g}, 1}^{\mathrm{DA}}=2.5 \mathrm{eV}$ and $E_{\mathrm{g}, \mathrm{h}}^{\mathrm{DA}}=2.95 \mathrm{eV}$, for compositions in the two-phase region containing $\mathrm{BiVO}_{4}$ and $\mathrm{Bi}_{4} \mathrm{~V}_{1.5} \mathrm{Fe}_{0.5} \mathrm{O}_{10.5}$. The identification of multiple band gaps from a single $T P^{\mathrm{DA}}$ spectrum is a unique feature of our algorithm, and in this instance, we observe excellent agreement between the phase behavior and the identification of multiple band gaps. While the lower band gap energy matches that of $\mathrm{BiVO}_{4}$, the higher band gap is larger than the $E_{\mathrm{g}}^{\mathrm{DA}}=2.7 \pm 0.1 \mathrm{eV}$ value noted above for $\mathrm{Bi}_{4} \mathrm{~V}_{1.5} \mathrm{Fe}_{0.5} \mathrm{O}_{10.5}$. We note that the estimation of the higher band gap energy in a multiband gap sample has an intrinsically large uncertainty due to the convolution of the band gap absorption onset with the above-gap absorption of the lowerband gap phase. This example provides an important demonstration that high throughput optical characterization with appropriate data analysis can provide insight into the underlying phase behavior.

Figure $4 \mathrm{e}$ shows $T P^{\mathrm{DA}}$ spectra for two samples with approximately $44 \%$ phase fraction of $\mathrm{FeVO}_{4}$, which are from the composition region with the lowest band gap energies in the library. Given the correlation of phase fraction and identification of a band gap near $2.25 \mathrm{eV}$, this band gap energy is certainly related to the presence of $\mathrm{FeVO}_{4}$. The lack of a higher phase-purity sample in the library limits the robust identification of the band gap energy. Literature reports for the direct band gap of this phase vary between 2.4 and $2.7 \mathrm{eV}^{26}$ Subgap absorption similar to that seen in Figure $4 \mathrm{e}$ has been 

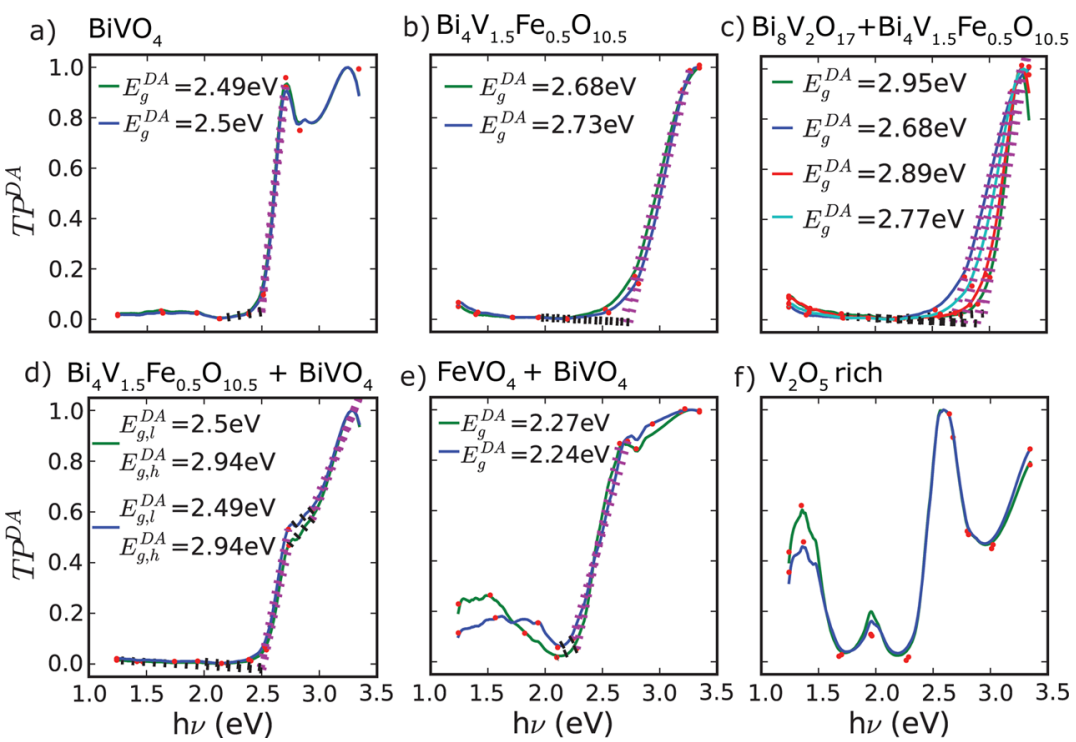

Figure 4. $T P^{\mathrm{DA}}$ spectra for compositions (a,b) representative of high phase purity $\mathrm{BiVO}_{4}$ and $\mathrm{Bi}_{4} \mathrm{~V}_{1.5} \mathrm{Fe}_{0.5} \mathrm{O}_{10.5}$, respectively, (c) in the two-phase $\mathrm{Bi}_{8} \mathrm{~V}_{2} \mathrm{O}_{17}+\mathrm{Bi}_{4}\left(\mathrm{~V}_{1.5} \mathrm{Fe}_{0.5} \mathrm{O}_{10.5}\right)$ region, (d) containing $\mathrm{BiVO}_{4}$ and $\mathrm{Bi}_{4}\left(\mathrm{~V}_{1.5} \mathrm{Fe}_{0.5} \mathrm{O}_{10.5}\right)$ phases, showing the identification of two-band gaps per composition, and (e) in the $\mathrm{FeVO}_{4}+\mathrm{BiVO}_{4}$ phase region with the highest phase fraction of $\mathrm{FeVO}_{4}(0.44)$ and (f) maxima and minima showing thin-film interference effect for $\mathrm{V}_{2} \mathrm{O}_{5}$-rich compositions. For $T P^{\mathrm{DA}}$ where at least one band gap is identified, the end points of the piecewise linear fit are highlighted as red circles. The Tauc line segment (dotted magenta), baseline segment (dotted black), and their intersection (whose abscissa is the estimate of the band gap) illustrate the band gap estimation procedure.

observed, ${ }^{27}$ although we note that this absorption could also be from the $\mathrm{BiVO}_{4}$ phase, which is also present in these samples. Overall, the observed structure-property relationships are in excellent qualitative and reasonable quantitative agreement with the literature.

For the $\mathrm{V}_{2} \mathrm{O}_{5}$-rich compositions of Figure $4 \mathrm{f}$, the $T P^{\mathrm{DA}}$ spectra contain multiple maxima and minima due to thin-film interference effects, and the exclusion of these samples from the band gap plot in Figure 3 illustrates the successful, automated identification of these spectra as lacking sufficient evidence of a direct-allowed optical transition.

In addition to providing a powerful demonstration of highthroughput, combinatorial mapping of structure-dependent optical properties, the most important discovery from the data in Figures 2-4 is the DA band gap of $2.7 \mathrm{eV}$ in the quaternary oxide $\mathrm{Bi}_{4} \mathrm{~V}_{1.5} \mathrm{Fe}_{0.5} \mathrm{O}_{10.5}$. Inspection of IA Tauc plots for the thin film samples reveals that this phase may have a IA band gap at slightly smaller energy (see Supporting Information), motivating more detailed analysis to reveal whether this is a direct or indirect semiconductor. Tetragonal $\mathrm{Bi}_{4} \mathrm{~V}_{1.5} \mathrm{Fe}_{0.5} \mathrm{O}_{10.5}$ consists of $\mathrm{Bi}_{2} \mathrm{O}_{2}$ slabs separated by layers that contain $(\mathrm{V}, \mathrm{Fe}) \mathrm{O}_{6}$ motifs (see Vesta ${ }^{28}$ drawing in Figure 5), and a similar arrangement is present in orthorhombic $\mathrm{Bi}_{4} \mathrm{~V}_{2} \mathrm{O}_{11}$. It has been hypothesized that the positive dipole moment from $\mathrm{BiO}_{4}$ units and the negative dipole moment from $\mathrm{VO}_{6}$ units along with the layered structure provide enhanced electron and hole transport in $\mathrm{Bi}_{4} \mathrm{~V}_{2} \mathrm{O}_{11}{ }^{29}$ In addition, substitution of $\mathrm{Fe}$ into the $\mathrm{VO}_{6}$ motif could improve catalysis of the oxygen evolution reaction (OER, the anodic reaction in solar water splitting cells), similar to the increase in catalytic activity observed for substitution of $\mathrm{Fe}$ in $\mathrm{NiO}_{6}$ motifs for $\mathrm{Ni}-\mathrm{Fe}-\mathrm{O}$ catalysts. ${ }^{30}$ First principle calculations of $\mathrm{Bi}_{4} \mathrm{~V}_{2} \mathrm{O}_{11}$ demonstrated that the valence band maximum is dominated by $\mathrm{O} 2 \mathrm{p}$ states with slight contribution from $\mathrm{Bi} 6 \mathrm{~s}$ states and that the conduction band minimum is mainly composed of $\mathrm{V} 3 \mathrm{~d}$ and $\mathrm{Bi} 6 \mathrm{p}$ states, ${ }^{29}$ which is consistent with the electronic structure of $\mathrm{BiVO}_{4}$. With a

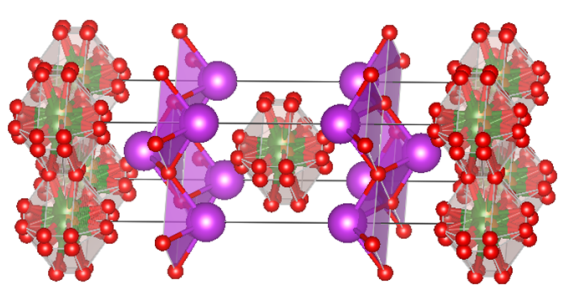

Figure 5. Crystal structure of $\mathrm{Bi}_{4} \mathrm{~V}_{1.5} \mathrm{Fe}_{0.5} \mathrm{O}_{10.5}$ showing $\mathrm{BiO}_{4}$ and $(\mathrm{V}, \mathrm{Fe}) \mathrm{O}_{6}$ motifs in alternating layers. Bi purple; $\mathrm{O}$ red; $\mathrm{V}, \mathrm{Fe}$ green $\left(\right.$ drawn in Vesta $\left.^{28}\right)$. Note that the $(\mathrm{V}, \mathrm{Fe}) \mathrm{O}_{6}$ motif has energetically degenerate sites for the metal atoms and corresponding partial occupancy of both $(\mathrm{V}, \mathrm{Fe})$ and $\mathrm{O}$ sites. The reader is referred to ICDD 01-087-1539 for detailed information about site occupancy factors.

slightly larger band gap, we expect that $\mathrm{Bi}_{4} \mathrm{~V}_{1.5} \mathrm{Fe}_{0.5} \mathrm{O}_{10.5}$ exhibits similar valence band and conduction band character. Given the rapid emergence of $\mathrm{BiVO}_{4}$ and recent study of $\mathrm{Bi}_{4} \mathrm{~V}_{2} \mathrm{O}_{11}$ as OER photoelectrocatalysts, the incorporation of catalytic sites into the crystal structure, and the excellent optical properties, this work identifies $\mathrm{Bi}_{4} \mathrm{~V}_{1.5} \mathrm{Fe}_{0.5} \mathrm{O}_{10.5}$ as a promising photoanode candidate for solar water splitting cells. We note that photoelectrochemical measurements were not possible in the present work since the materials were deposited onto an insulating substrate and that the optical properties of the phases reported could depend on processing conditions due to thin film effects such as strain and polycrystallinity.

\section{SUMMARY}

A HiTp light absorber discovery platform featuring the combination of XRD and optical characterization was applied to a $(\mathrm{Bi}-\mathrm{V}-\mathrm{Fe}) \mathrm{O}_{x}$ continuous composition spread thin-film library. Demonstrated features of the HiTp methodology include (1) identification of a direct band gap at compositions exhibiting a large phase concentration of $\mathrm{BiVO}_{4}, \mathrm{FeVO}_{4}$, or $\mathrm{Bi}_{4} \mathrm{~V}_{1.5} \mathrm{Fe}_{0.5} \mathrm{O}_{10.5} ;$ (2) validation of the techniques through comparison of HiTp data with properties of known phases, in 
particular, $\mathrm{BiVO}_{4}$; (3) illustrative examples of Tauc analysis in multiphase regions; and (4) successful automated flagging of low-absorption samples. The structure-band gap mapping revealed a direct band gap of $2.7 \pm 0.1 \mathrm{eV}$ for the thin-film quaternary oxide $\mathrm{Bi}_{4} \mathrm{~V}_{1.5} \mathrm{Fe}_{0.5} \mathrm{O}_{10.5}$, a known multifunctional material that has now been identified as a promising optical and photoelectrochemical material. The rapid mapping of band gaps for higher-order composition spaces provides rapid access to relatively unexplored material spaces for a variety of applications, most notably light absorbers for renewable energy technologies. Such data sets also provide important data with necessary volume, velocity, variety, and veracity for the development of materials theory and informatics efforts, as envisioned by the Materials Genome Initiative.

\section{ASSOCIATED CONTENT}

\section{S Supporting Information}

The Supporting Information is available free of charge on the ACS Publications website at DOI: 10.1021/acscombsci.6b00054.

Indirect allowed Tauc analysis for monoclininc $\mathrm{BiVO}_{4}$ and $\mathrm{Bi}_{4} \mathrm{~V}_{1.5} \mathrm{Fe}_{0.6} \mathrm{O}_{10.5}$ phases (PDF)

Data used to generate figures (ZIP)

\section{AUTHOR INFORMATION}

\section{Corresponding Author}

*E-mail: gregoire@caltech.edu.

\section{Notes}

The authors declare no competing financial interest.

\section{ACKNOWLEDGMENTS}

This manuscript is based upon work performed by the Joint Center for Artificial Photosynthesis, a DOE Energy Innovation Hub, supported through the Office of Science of the U.S. Department of Energy (Award No. DE-SC0004993). Use of the Stanford Synchrotron Radiation Lightsource, SLAC National Accelerator Laboratory, is supported by the US Department of Energy, Office of Science, Office of Basic Energy Sciences under Contract No. DE-AC02-76SF00515. The authors thank Ryan Jones, Chad Miller, Samuil Belopolskiy, and Tim Dunn for assistance with the synchrotron experiments.

\section{REFERENCES}

(1) Green, M. L.; Takeuchi, I.; Hattrick-Simpers, J. R. Applications of high throughput (combinatorial) methodologies to electronic, magnetic, optical, and energy-related materials. J. Appl. Phys. 2013, 113 (23), 231101-231101.

(2) (a) Walter, M. G.; Warren, E. L.; McKone, J. R.; Boettcher, S. W.; Mi, Q.; Santori, E. A.; Lewis, N. S. Solar water splitting cells. Chem. Rev. 2010, 110 (11), 6446-6473. (b) Hautier, G.; Fischer, C. C.; Jain, A.; Mueller, T.; Ceder, G. Finding Nature's Missing Ternary Oxide Compounds Using Machine Learning and Density Functional Theory. Chem. Mater. 2010, 22 (12), 3762-3767. (c) Peng, H.; Ndione, P. F.; Ginley, D. S.; Zakutayev, A.; Lany, S. Design of Semiconducting Tetrahedral Mn1-xZnxO Alloys and Their Application to Solar Water Splitting. Phys. Rev. X 2015, 5 (2), 021016. (d) Setyawan, W.; Curtarolo, S. High-throughput electronic band structure calculations: Challenges and tools. Comput. Mater. Sci. 2010, 49 (2), 299-312. (e) Curtarolo, S.; Hart, G. L. W.; Nardelli, M. B.; Mingo, N.; Sanvito, S.; Levy, O. The high-throughput highway to computational materials design. Nat. Mater. 2013, 12 (3), 191-201.

(3) Zakutayev, A.; Zhang, X.; Nagaraja, A.; Yu, L.; Lany, S.; Mason, T. O.; Ginley, D. S.; Zunger, A. Theoretical prediction and experimental realization of new stable inorganic materials using the inverse design approach. J. Am. Chem. Soc. 2013, 135 (27), 10048-54.

(4) (a) Suram, S. K.; Haber, J. A.; Jin, J.; Gregoire, J. M. Generating Information Rich High-Throughput Experimental Materials Genomes using Functional Clustering via Multi-Tree Genetic Programming and Information Theory. ACS Comb. Sci. 2015, 17 (4), 224-233. (b) Rajan, K. Combinatorial Materials Sciences: Experimental Strategies for Accelerated Knowledge Discovery. Annu. Rev. Mater. Res. 2008, 38 (1), 299-322.

(5) (a) Haber, J. A.; Cai, Y.; Jung, S.; Xiang, C.; Mitrovic, S.; Jin, J.; Bell, A. T.; Gregoire, J. M. Discovering Ce-rich oxygen evolution catalysts, from high throughput screening to water electrolysis. Energy Environ. Sci. 2014, 7 (2), 682-688. (b) Liu, X. N.; Shen, Y.; Yang, R T.; Zou, S. H.; Ji, X. L.; Shi, L.; Zhang, Y. C.; Liu, D. Y.; Xiao, L. P.; Zheng, X. M.; Li, S.; Fan, J.; Stucky, G. D. Inkjet Printing Assisted Synthesis of Multicomponent Mesoporous Metal Oxides for Ultrafast Catalyst Exploration. Nano Lett. 2012, 12 (11), 5733-5739.

(6) (a) Kirby, S.; Vandover, R. Improved conductivity of $\mathrm{ZnO}$ through codoping with In and Al. Thin Solid Films 2009, 517 (6), 1958-1960. (b) Taylor, M. P.; Readey, D. W.; Teplin, C. W.; van Hest, M. F. a. M.; Alleman, J. L.; Dabney, M. S.; Gedvilas, L. M.; Keyes, B. M.; To, B.; Parilla, P. a.; Perkins, J. D.; Ginley, D. S. Combinatorial Growth and Analysis of the Transparent Conducting Oxide $\mathrm{ZnO} / \mathrm{In}(\mathrm{IZO})$. Macromol. Rapid Commun. 2004, 25 (1), 344347.

(7) Fioretti, A. N.; Zakutayev, A.; Moutinho, H.; Melamed, C.; Perkins, J. D.; Norman, A. G.; Al-Jassim, M.; Toberer, E. S.; Tamboli, A. C. Combinatorial insights into doping control and transport properties of zinc tin nitride. J. Mater. Chem. C 2015, 3 (42), 1101711028.

(8) (a) Anderson, A. Y.; Bouhadana, Y.; Barad, H.-N.; Kupfer, B.; Rosh-Hodesh, E.; Aviv, H.; Tischler, Y. R.; Rühle, S.; Zaban, A. Quantum Efficiency and Bandgap Analysis for Combinatorial Photovoltaics: Sorting Activity of $\mathrm{Cu}-\mathrm{O}$ Compounds in All-Oxide Device Libraries. ACS Comb. Sci. 2014, 16 (2), 53-65. (b) Majhi, K.; Bertoluzzi, L.; Rietwyk, K. J.; Ginsburg, A.; Keller, D. A.; Lopez-Varo, P.; Anderson, A. Y.; Bisquert, J.; Zaban, A. Combinatorial Investigation and Modelling of $\mathrm{MoO} 3$ Hole-Selective Contact in TiO2lCo3O4I MoO3 All-Oxide Solar Cells. Adv. Mater. Interfaces 2016, 3 (1), 1500405.

(9) Haussener, S.; Xiang, C.; Spurgeon, J. M.; Ardo, S.; Lewis, N. S.; Weber, A. Z. Modeling, simulation, and design criteria for photoelectrochemical water-splitting systems. Energy Environ. Sci. 2012, 5 (12), 9922-9935.

(10) Mitrovic, S.; Cornell, E. W.; Marcin, M. R.; Jones, R. J.; Newhouse, P. F.; Suram, S. K.; Jin, J.; Gregoire, J. M. High-throughput on-the-fly scanning ultraviolet-visible dual-sphere spectrometer. Rev. Sci. Instrum. 2015, 86 (1), 013904.

(11) Srinivasan, S.; Rajan, K. Property Phase Diagrams" for Compound Semiconductors through Data Mining. Materials 2013, 6, 279-290.

(12) (a) Isaacs, E. D.; Marcus, M.; Aeppli, G.; Xiang, X.-D.; Sun, X.D.; Schultz, P.; Kao, H.-K.; Cargill, G. S.; Haushalter, R. Synchrotron $\mathrm{x}$-ray microbeam diagnostics of combinatorial synthesis. Appl. Phys. Lett. 1998, 73, 1820. (b) Kukuruznyak, D. A.; Reichert, H.; Okasinski, J.; Dosch, H.; Chikyow, T.; Daniels, J.; Honkimäki, V. Highthroughput screening of combinatorial materials libraries by highenergy x-ray diffraction. Appl. Phys. Lett. 2007, 91, 071916. (c) Gregoire, J. M.; Dale, D.; Kazimirov, A.; DiSalvo, F. J.; van Dover, R. B. High energy $\mathrm{x}$-ray diffraction/x-ray fluorescence spectroscopy for high-throughput analysis of composition spread thin films. Rev. Sci. Instrum. 2009, 80 (12), 123905.

(13) Gregoire, J. M.; Van Campen, D. G.; Miller, C. E.; Jones, R.; Suram, S. K.; Mehta, A. High Throughput Synchrotron X-ray Diffraction for Combinatorial Phase Mapping. J. Synchrotron Radiat. 2014, 21 (6), 1262-1268.

(14) Thienhaus, S.; Naujoks, D.; Pfetzing-Micklich, J.; Konig, D.; Ludwig, A. Rapid identification of areas of interest in thin film materials libraries by combining electrical, optical, X-ray diffraction, 
and mechanical high-throughput measurements: a case study for the system Ni-Al. ACS Comb. Sci. 2014, 16 (12), 686-94.

(15) Fujishima, A.; Honda, K. Electrochemical Photolysis of Water at a Semiconductor Electrode. Nature 1972, 238 (5358), 37-38.

(16) Hu, S.; Xiang, C.; Haussener, S.; Berger, A. D.; Lewis, N. S. An analysis of the optimal band gaps of light absorbers in integrated tandem photoelectrochemical water-splitting systems. Energy Environ. Sci. 2013, 6 (10), 2984-2984.

(17) Gregoire, J. M.; Dale, D.; Kazimirov, A.; DiSalvo, F. J.; van Dover, R. B. Cosputtered composition-spread reproducibility established by high-throughput x-ray fluorescence. J. Vac. Sci. Technol., A 2010, 28 (5), 1279-1280.

(18) Cooper, J. K.; Gul, S.; Toma, F. M.; Chen, L.; Liu, Y.-S.; Guo, J.; Ager, J. W.; Yano, J.; Sharp, I. D. Indirect Bandgap and Optical Properties of Monoclinic Bismuth Vanadate. J. Phys. Chem. C 2015, 119 (6), 2969-2974.

(19) Mannsfeld, S. C.; Tang, M. L.; Bao, Z. Thin film structure of triisopropylsilylethynyl-functionalized pentacene and tetraceno[2,3b]thiophene from grazing incidence X-ray diffraction. Adv. Mater. 2011, 23 (1), 127-31.

(20) Hattrick-Simpers, J. R.; Gregoire, J. M.; Kusne, A. G. Perspective: Composition-structure-property mapping in highthroughput experiments: Turning data into knowledge. APL Mater. 2016, 4 (5), 053211.

(21) Le Bras, R.; Bernstein, R.; Gregoire, J. M.; Suram, S. K.; Gomes, C. P.; Selman, B.; van Dover, R. B. A Computational Challenge Problem in Materials Discovery: Synthetic Problem Generator and Real-World Datasets. Proceedings of the Twenty-Eighth Conference on Artificial Intelligence (AAAI-14), Québec City, Canada; AAAI Press: Palo Alto, CA, 2014.

(22) Kubelka, P. New Contributions to the Optics of Intensely LightScattering Materials. Part I. J. Opt. Soc. Am. 1948, 38 (5), 448-457.

(23) Brack, P.; Sagu, J. S.; Peiris, T. A. N.; McInnes, A.; Senili, M.; Wijayantha, K. G. U.; Marken, F.; Selli, E. Aerosol-Assisted CVD of Bismuth Vanadate Thin Films and Their Photoelectrochemical Properties. Chem. Vap. Deposition 2015, 21 (1-2-3), 41-45.

(24) Joubert, O.; Ganne, M.; Vannier, R. N.; Mairesse, G. Solid phase synthesis and characterization of new BIMEVOX series: Bi4V2 $\mathrm{xMxO} 11-\mathrm{x}(\mathrm{M}=\mathrm{CrIII}$, FeIII). Solid State Ionics 1996, 83 (3-4), 199-207.

(25) Fortalnova, E. A.; Murasheva, V. V.; Safronenko, M. G.; Venskovskii, N. U.; Kaleva, G. M.; Stefanovich, S. Y.; Politova, E. D. Study of ferroelectric phase transitions in solid solutions based on bismuth vanadate. Bull. Russ. Acad. Sci.: Phys. 2008, 72 (8), 10941097.

(26) (a) Tong, Y.; Tang, P. S. Synthesis of Nanocrystalline FeVO4 and Its Visible-Light Photocatalytic Activity. Adv. Mater. Res. 2012, 486, 124-128. (b) Dixit, A.; Chen, P.; Lawes, G.; Musfeldt, J. L. Electronic structure and polaronic excitation in FeVO4. Appl. Phys. Lett. 2011, 99 (14), 141908.

(27) Morton, C. D.; Slipper, I. J.; Thomas, M. J. K.; Alexander, B. D. Synthesis and characterisation of $\mathrm{Fe}-\mathrm{V}-\mathrm{O}$ thin film photoanodes. $J$. Photochem. Photobiol., A 2010, 216 (2-3), 209-214.

(28) Momma, K.; Izumi, F. VESTA 3 for three-dimensional visualization of crystal, volumetric and morphology data. J. Appl. Crystallogr. 2011, 44 (6), 1272-1276.

(29) Jiang, Z.; Liu, Y.; Li, M.; Jing, T.; Huang, B.; Zhang, X.; Qin, X.; Dai, Y. One-Pot Solvothermal Synthesis of Bi4V2O11 as A New Solar Water Oxidation Photocatalyst. Sci. Rep. 2016, 6, 22727.

(30) Friebel, D.; Louie, M. W.; Bajdich, M.; Sanwald, K. E.; Cai, Y.; Wise, A. M.; Cheng, M.-J.; Sokaras, D.; Weng, T.-C.; Alonso-Mori, R.; Davis, R. C.; Bargar, J. R.; Nørskov, J. K.; Nilsson, A.; Bell, A. T. Identification of Highly Active $\mathrm{Fe}$ Sites in $(\mathrm{Ni}, \mathrm{Fe}) \mathrm{OOH}$ for Electrocatalytic Water Splitting. J. Am. Chem. Soc. 2015, 137 (3), 1305-1313. 